\title{
Advancement of Hydro-Desulfurization Catalyst and Discussion of Its Application in Coal Tar
}

\author{
Zongkuan Liu, Lei Zhang*, Jian Jiang, Cheng Bian, Zichao Zhang, Zifeng Gao \\ Chemical Engineering Department, School of Chemical Engineering, Xi'an Jiaotong University, Xi'an, China \\ Email: ${ }^{*}$ zhanglei.xjtu.imu@gmail.com
}

Received September 2, 2012; revised October 1, 2012; accepted October 10, 2012

\begin{abstract}
This paper describes the influences of active metal, promoter and chelating agent on the properties of hydro-desulfurization catalyst. The use of chelating agent, especially its combination with common promoters e.g., EDTA-P, has an important meaning to develop highly active catalyst, specifically to unify the active metal dispersion degree and sulfurization degree in some extent, however, they are contradictory in conventional cognition. In the aspect of carriers, composition and nanometer carriers have more excellent performances in acidity, pores structure and metal-carrier interaction than common carriers, and are the developing trend in the future and should be a breakthrough mainly in preparation methods. We also pointed out the decisive factors to improve the activity of the catalyst: higher sulfurization degree of active metal oxide and higher aspect ratios of active phase crystal morphology, and the proper acidity and pores structure can be considered the key factors for deep desulfurization whose mainly obstacle is the desulfurization of large rigid molecules, e.g., dibenzothiophene and 4, 6-dimethyl substituted dibenzothiophene. Based on above that, We discussed the suitable hydrodesulfurization (HDS) catalyst for coal tar, aiming at providing some theoretical guidance for the "design" of coal tar HDS catalyst.
\end{abstract}

Keywords: Carrier; Active Metal; Promoter and Chelating Agent; HDS Catalyst; Metal-Carrier Interaction; Coal Tar

\section{Introduction}

China's current energy situation is rich in coal, lack of natural gas and less of oil. In recent years, with the development of the national economy, the contradiction between supply and demand of oil and gas resources is more and more prominent. Using coal tar to prepare fuel oil will alleviate the energy crisis in a certain extent. Coal tar is the main byproduct of coal gasification and coal coking process, its output was about 15 million tons with the annual growth rate about $13.68 \%$ in 2009 in China [1, 2].

Hydrotreating is the main technology to prepare fuel oil from coal tar, and hydrodesulfurization (HDS) is an important link in the process of which core is HDS catalyst. Traditional HDS catalyst does increasingly not meet the requirements and the following two reasons could account for it: on one hand, coal tar is heavy and the unsaturated compounds which are abundant in coal tar have evil influences (resinification reaction reacts between unsaturated compounds and chemical reagent, and thus creating much precipitation and slagging) on coal tar hydro-refining [2]; on the other hand, the environmental protection laws are more and more strict with sulfur con-

${ }^{*}$ Corresponding author. tent of fuel oil. Pawelec et al. [3] pointed out that the activity of the new catalyst should be 3.2 times the conventional catalyst when requiring diesel sulfur content reduces from $500 \mathrm{ppm}$ to $15 \mathrm{ppm}$ with not changing the technological parameters. It is press for designing and developing new HDS catalyst. HDS catalyst includes loaded type and un-loaded type, this paper mainly studied on the former.

The catalyst design process is very complex. In the past, preparation of catalyst depends on the rich "formula" experiences; in recent years, along with the development of surface physics, surface chemistry and organic catalytic mechanism, as well as the use of precision instrument in catalyst characterization, making catalyst "design" be possible. The components that can be distinguished in the catalyst include active metal, promoter or chelating agent and carrier.

Active metal is the main source of hydrogenation activity, it should be chosen according to the properties of raw oils or model molecules and product quality standards [4-12]. Promoter is an important part of the catalyst and a lot of confidential materials are concentrated in it. It is essential to optimize its kinds and content in the process of catalyst preparation [13-22]. The available carriers in HDS catalyst are as the following types ac- 
cording to the chemical compositions: silicon-aluminum molecular sieves $[23,24]$, metallic oxides [25,26], mesoporous silica molecular sieves $[10,11,27,28]$ and composites made up by these materials $[7,8,23,26]$. The most significant characteristics of carriers are its ability to disperse metal and possession of B, L type acids. These two kinds of acids play different roles in hydrogenation reaction, but synergy exists between them [29].

The three parts of catalyst are interrelation and interaction. Hence, a comprehensive consideration should be given in the process of catalyst preparation. In the actual process of catalyst "design", "Attending to one thing and losing sight of another" is a frequently encountered problem. For one instance, weak metal-carrier interaction is beneficial to the improvement of sulfurization degree of the active metal oxide, but the dispersion degree of the active phase may be reduced. For another instance, although large pores can weaken the diffusion resistance and reduce secondary cracking of the reactant molecules, that would make the initial activity of the catalyst and the metal capacity of carrier reduced. Consequently, the problem of the catalyst "design" is actually an "optimization" problem. The objective function should be the maximization of enterprise's interests, the constraint conditions should be the nature of raw oils, quality standards of products and laws of environmental protection, and the optimization variables are main parameters of catalyst design: metal types, metal content and crystal morphology of active phase, promoter or chelating agent types and content, and carrier's surface properties. The main purpose of this paper is to provide certain theoretical guidance for the preparation of coal tar HDS catalyst on the basis of system analysis and introduction of the main parameters of the HDS catalyst.

\section{Active Components}

\subsection{Conventional Active Components}

In general, conventional hydrogenation active sites include the simple substance of noble metal and non-noble metal sulfide. But the use of noble metal is limited to some extent because of its expensive price. So, keep the activity of noble metals catalyst not decline while making the consumption of noble metals reduced is the goal that researchers always pursue. In this respect, Nakamura, et al. [30] proposed a nanometer-catalyst technology to reduce the dosage of noble metals. Its specific process was schematically shown in Figure 1. Its basic concept is that the catalyst is made up of the substrate to restrain the sintering of noble metal and the separation material to inhibit the agglutination of the substrate. The structure can greatly reduce the dosage of noble metal because it can keep noble metal be nanometer particle. To make an appropriate bonding force between metal and carrier is its key point, because it is not conducive to improving the catalytic activity whether the bonding force is too strong or too weak, and thus selecting a proper carrier is important. Weak resistance capability to sulfur is the other reason resulting in its limited application. Some studies [8,9] showed that the resistance capability to sulfur can be enhanced when catalyst possesses smaller metal particles, proper acidity (mainly Lewis acid sites with high electronegativity) and formation of alloy. This may relate to the inhibition of generation of low activity $\mathrm{Pd}_{4} \mathrm{~S}$ in these circumstances.

Co-Mo-S, Ni-Mo-S and Mo-Ni-W-S are commonly used active phases of non-noble metal HDS catalysts. In general, their hydro-refining activity increases as the sequence $[4,5,31,32]$. This may because different promoter metals (Co, Ni) have different modulation ability to S-metal bonding energy. Literature [3] confirmed this view and pointed out that the change process of the activity of $\mathrm{Co}(\mathrm{Ni}) \mathrm{Mo}(\mathrm{W}) \mathrm{S}$ is a volcano curve with the enhancement of S-metal bonding energy. Therefore, moderate S-metal bonding strength is one of the crucial factors to improve the catalytic activity.

\subsection{Non-Noble Metal Phosphide and Noble Metal Phosphide}

Metal phosphides are commonly obtained through the reduction of their corresponding oxides or chlorides by temperature-programmed method in $\mathrm{H}_{2}$ atmosphere [33, 34]. The reduction temperature affects the particle size of active phase and hence has significant implications to

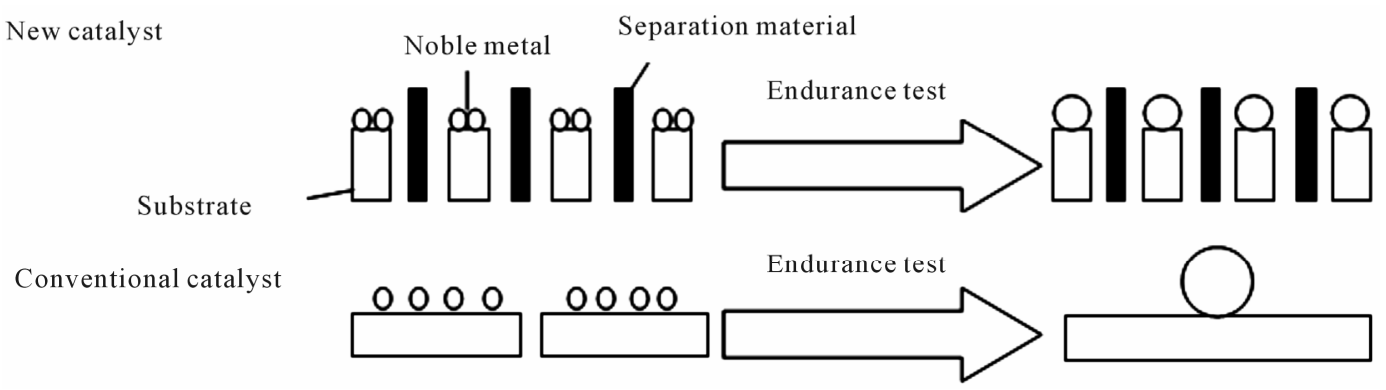

Figure 1. The new catalyst design concept about restraining sintering of the noble metal. 
HDS activity; therefore, selecting an appropriate reduction atmosphere to lower the reduction temperature is momentous.

Non-noble metal phosphides have highly HDS activity which is higher than normal $\mathrm{Co}(\mathrm{Ni}) \mathrm{Mo}(\mathrm{W}) \mathrm{S}$. Particularly, the activity of crystalline $\mathrm{Ni}_{2} \mathrm{P}$ is the highest among them because of its higher intrinsic activity and dispersion degree compared to the other phosphides [10]; Another advantage of $\mathrm{Ni}_{2} \mathrm{P}$ is its HDS activity will not be inhibited with the competition of HDN (hydrodenitrification) $[4,6,10]$. Inversely, the HDS activity of $\mathrm{Co}(\mathrm{Ni}) \mathrm{Mo}(\mathrm{W}) \mathrm{S}$ would be restricted due to the competition of nitrogen compounds in $\mathrm{H}$ and the edges of active phase [35]. The disadvantage of $\mathrm{Ni}_{2} \mathrm{P}$ is its very low dispersion degree, only $1 / 3$ times the active phases of industrial hydrotreating catalyst. Consequently, to improve its dispersion degree is the key to its practical application. JI research group [13-16] have studied the influences of $\mathrm{W}, \mathrm{Mo}, \mathrm{Li}$, $\mathrm{Na}, \mathrm{K}, \mathrm{Mg}, \mathrm{Ca}, \mathrm{Sr}, \mathrm{Ba}$ and $\mathrm{B}$ on the dispersion degree of $\mathrm{Ni}_{2} \mathrm{P}$ based on SBA-15, manifesting that $\mathrm{W}, \mathrm{Mo}, \mathrm{Ca}$ and $\mathrm{B}$ promoted its dispersion degree, and thus the HDS activity of the catalyst was enhanced, but that property is closely related to the promoters content (as the discussion in 5.1.3 in this paper); In addition, $\mathrm{Ni} / \mathrm{P}$ molar ratio is also a major parameter in process of the catalyst preparation because of its affection on the types of active phases. If the ratio is too high, there will be more formation of low active $\mathrm{Ni}_{12} \mathrm{P}_{5}$. In general, this ratio is between 1.2 - $1.4[6,13,14,36]$, and is lower than the ideal ratio 2 .

Recently, it is worth mentioning that Kanda et al. [33] synthesized a series of noble metal phosphides: Rh-P, Pd-P, Ru-P, Pt-P. They made the corresponding noble metal chloride precursors primarily decomposed in $\mathrm{N}_{2}$ atmosphere, and then reduced by temperature-programmed method in $\mathrm{H}_{2}$ atmosphere. Their HDS activity for thiophene follows the order: Rh-P $>$ Pd-P $>$ Ru-P $>$ Pt-P, activity and stability of Rh-P are the best and are better than Ni-P.

\subsection{Non-Noble Metal Carbides and Nitrides}

Chemical bond in carbides and nitrides has part of the properties of metal bond. Their preparation methods mainly differ in the reaction atmosphere and temperature [12]. Nitrides are commonly generated in $\mathrm{NH}_{3}$ and $\mathrm{N}_{2}$ atmosphere, the former's advantage over the latter's is to inhibit the formation of impurities and lower the reduction temperature. The formation process of carbides is the oxide precursors reduced primarily by temperatureprogrammed method in $\mathrm{CH}_{4}-\mathrm{H}_{2}$ atmosphere, and then utilize $\mathrm{N}_{2}$ containing low quantity of $\mathrm{O}_{2}$ of which volume fraction is less than $1 \%$ to passivate the carbides. One of the remarkable properties of metal carbides is to embellish the acidity of silica-aluminum molecular sieves [20,
21].

\subsection{Others}

Lan et al. [4] made $\mathrm{Ni}_{2} \mathrm{P}$ and $\mathrm{Mo}-\mathrm{Ni}-\mathrm{W}$ combined catalyst $\mathrm{Ni}_{2} \mathrm{P}-\mathrm{NiMoW} / \gamma-\mathrm{Al}_{2} \mathrm{O}_{3}$ which showed more excellent performances than conventional catalysts, that is, it can make diesel oil achieve deep desulfurization, simultaneously, the increase of cetane number.

$\mathrm{ReS}_{2}$ also can be used for hydrogenation active site of HDS catalyst. Its HDS activity is positive correlation to the carrier's ratio of silica to aluminium, i.e., the acidity of the catalyst plays an inhibitory role for HDS activity [7], but oppositely for traditional HDS catalysts [28,37].

\section{The Content of Active Components}

Metal content including total metals content and the proportion of different metals in one catalyst is an important parameter in catalyst design process. Metal content usually affects the dispersive state of active metal, and the dispersive state would also impact the acids distribution [38], metal-support interaction [39] and the number of hydrogenation active sites etc. Overall, a highly active catalyst should be higher total metals content and appropriate metal dispersion degree, i.e., in the case of the excellent dispersion state of active metals, the higher total metals content is conducive to improving the catalytic activity.

\subsection{Influences on Acids}

In normal circumstances, the appropriate acids distribution and moderate acidity strength are beneficial to HDS activity of catalyst. That is because, on one hand, B, L acids are in favor of the adsorption of reactant molecules [28] and hydrogen overflow, and thus are useful to cleave C-S $[37,40]$; on the other hand, the acids can make the alkyl-substituted dibenzothiophene (DBTs) isomerize to molecules owning weaker steric hindrance for -S-.

There are three regulation mechanisms of metal active on acid amount and acids type: to generate new acid, ion exchange and covering effect. Acidity is changed as the change of metal content. When the active metal content increases within a certain range, the amount of $\mathrm{L}$ acid (weak acid) is increased but inversely for B acid [4,41]. The increase of $\mathrm{L}$ acid amount is due to the empty orbits in active metals which can generate Lewis acid that is different from the Lewis acid site centering in $\mathrm{Al}_{3}^{+}$; the reduction amount of $\mathrm{B}$ acid is because of ion exchange between metal cation and proton, along with covering effect of metal components on part of Si-OH-Al (strong $\mathrm{B}$ acid center) and $\mathrm{OH}-\mathrm{Si}$ (weak B acid site); Study [28] on the acids distribution of NiW/Al-SBA-15 and Al- 
SBA-15 proved this point, the former's L, B acid amount are 1.6, 0.5 times the latter, respectively. Study in literature [38] also supported this view. But literature [42] showed that the active metal also made B acid amount increase, this may relate to the conversion of tetra-coordinate metal species on the support surface [43].

\subsection{The Consideration for Metals Content Ratio}

There is synergistic effect in multi-components active metal catalyst, and the effect can make catalyst be better performance. e.g., HDS activity of $\mathrm{PdAu} / \mathrm{HS}-\mathrm{HMS}$ for thiophene was three times Pd/HS-HMS due to the synergistic effect between $\mathrm{Pd}$ and $\mathrm{Au}$ [9], and the deactivation rate of the former was also significantly lower than the latter. The main reason is that the former has the formation of the alloy made up of $\mathrm{Pd}$ and $\mathrm{Au}$, and thus inhibits formation of $\mathrm{PdS}_{4}$. The synergy closely relates to the metals content ratio. Consequently, both the total content and ratios of the metals content should be taken into account in the process of catalyst design. Literatures [44, 45] discussed the impact of molar ratios of $\mathrm{Pt} /(\mathrm{Pt}+\mathrm{Pd})$ and $\mathrm{Ni} /(\mathrm{Ni}+\mathrm{W})$ on the catalytic activity, demonstrating that the former or the latter possessed the highest hydrogenation activity for naphthalene or HDS activity for thiophene when the ratios are 0.7 or 0.28 , respectively. Study on $\mathrm{Mo}-\mathrm{Ni}_{2} \mathrm{P} / \mathrm{SBA}-15 /$ cordierite monolithic catalyst [16] indicated that its HDS activity for DBT was optimal when the molar ratio of $\mathrm{Mo} / \mathrm{Ni}+\mathrm{Mo}$ was 0.18 , however, when the ratio was 0.26 in $\mathrm{NiMo} / \mathrm{Al}_{2} \mathrm{O}_{3}-\mathrm{nmY}$, the optimal desulfurization degree of diesel was up to $99.6 \%$ [23]. Through the latter two examples, we can find that the ratios of $\mathrm{Mo} / \mathrm{Ni}+\mathrm{Mo}$ are different, that may because the active phases are different in the two catalysts. So, the ratio is not invariable, and should be optimized in accordance with the active phase v carrier and preparation method.

\section{The Active Phase Crystal Morphology}

The active phase crystal morphology has vital influence on the activity of the catalyst. It is closely relevant to the types and amount of the active phases, as well as the number of the corner and edge active sites and lattice defects. In addition, it can also determine whether the hydrogenation active sites can be well exposed to the reactant molecules or not. The main parameters used to describe the active phase crystal morphology include stacking degree, length and curvature of the lamellae.

Stacking degree has major impact on the types of active phase and the amount of corner and edge active sites. Generally speaking, multilayer stacking shows better performance than the single-layer. This is mainly manifested in two aspects: First, multilayer stacking can generate more type II active sites than the single-layer due to its weaker interaction with carrier except the basal layer [46]. The top layer possesses the highest activity because of the weakest steric hindrance and higher unsaturation degree of the brim and corners active sites [8], in addition, the top layer and middle layers also differ in the desulfurization mechanism, the brim of the top layer owns capability of DDS (direct desulfurization) and HY $\mathrm{D}$ (hydrogenation desulfurization) routes while the middle layers only have DDS activity [47]. Second, multilayer stacking can produce more lattice defects compared to monolayer stacking and thus is beneficial to chemisorption [26,28]. However, the number of stacking layers is not the more the better; too many stacking layers will lead to a ratio decrease of vertical adsorption, as well as the corners and edges active sites [8,39,47]. Therefore, it is major to optimize stacking layers in order to balance the amount of corners and edges active sites and II type active sites.

However, the multi-layer stacking is not the necessary condition to produce type II active sites. Sometimes, monolayer stacking may be the II active sites. Parola et al. [48] pointed out the prerequisite of generating type II active sites is weaker metal-carrier interaction. Moreover, in case of inherently weak metal-support interaction, the increase of active phase stacking layers, sometimes, leads to a detriment effect on its HDS activity [28], Study [8] about NiMo-NTA $/ \mathrm{Al}_{2} \mathrm{O}_{3}$ (NTA = nitrilo triacetic acid that can significantly weaken the metal-carrier interaction) showed that its intrinsic HDS activity for DBT significantly reduced with the increase of active phase stacking layers because of activity of the top layer higher than others, and more stacking layers may mean lower proportion of the top layer [26]. Nevertheless, when the stacking layers are few, it is not conducive to the plane adsorption of reactant of catalyst $[25,28]$. Therefore, even in the case of weak intrinsic metal-support interaction, and hence generating a large number of type II active sites, an optimal point of the stacking layers should also exists, rather than the fewer the better.

In short, stacking layers of the active phase has important influences on HDS activity. However, the relation between active phase crystal morphology and HDS activity can't be determined only depending on the stacking degree of the crystal morphology. Shimada et al. [46] summarized the relation, indicating that the higher aspect ratios (approximately equal to the thickness divided by length) of the crystal morphology, the higher intrinsic activity of the catalyst. Many studies [5,23,26,28,32,49] have supported the view. That may because this kind of crystal morphology can maximize the amount of corner and edge active sites, and weaken steric hindrance of the active sites so that it could be well exposed to the reactant molecules, as well as generate more type II active sites. Finally, we can also safely get such a conclusion 
according to those literatures: moderate metal-support interaction is the decisive factor for achieving of the highest aspect ratios of crystal morphology.

The bending of the active phase lamellae also has an important impact on HDS activity and HDS mechanism [47]. This is because, on one hand, the curved lamellae would make the edge of metal layer expose more active sites, on the other hand, it make the S-Mo (W) bond tight, and thereby increasing the unsaturation degree of the active metal and hence creating new active sites.

\section{Promoters and Chelating Agents}

\subsection{Promoters}

The modulation capability of promoters for catalyst performances is not only relevant to the nature of the promoter itself and quantity of the promoter, but also connected with the impregnation order of active metal and the promoter $[18,19,22,50,51]$

\subsubsection{Influences on Metal-Support Interaction}

Metal-support interaction is the decisive factor to the sulfurization degree and crystal morphology of active metal. Therefore, utilizing promoter to modulate metalsupport interaction is important. In general, the modulation of the metal-support interaction actually refers to "weaken" this interaction.

Metal-support interaction is modulated by promoter mainly in three ways: First, it can be weakened by modulating the coordination state of active metal. Different coordination states of the active metal bring about different intensity of metal-support interaction, more specifically, tetrahedron coordinated active metal species commonly have stronger binding force with support than octahedron species [26,28]. P modulates the metal-carrier interaction is just through that mechanism [19]. But the improvement degree of metal-support interaction is mainly associated with the impregnation sequence of $\mathrm{P}$ [18], to be specific, co-impregnation improvement capacity is higher than the surface impregnation; second, metalsupport interaction is modulated through synergy effect between the active metal and promoter, the promoters mainly should be transition metals, e.g., Fe [50], Co [51]. To these promoters, The content must be suitable because excessive content of promoter may inversely strengthen the metal-support interaction due to the improvement of the dispersion degree of active phase in this case [50]; third, promoters could achieve the modulation ability through "isolation" of the active metal and support in physical space. For B modified catalyst B-MoNi/ $\mathrm{Al}_{2} \mathrm{O}_{3}$ and $\mathrm{MoNi}-\mathrm{B} / \mathrm{Al}_{2} \mathrm{O}_{3}$ [22], the former which impregnated $\mathrm{B}$ and $\mathrm{MoNi}$ in sequence has better modulation capability than the latter. This is because B (w0.6\%) could be monolayer distribution on the carrier surface in
$\mathrm{B}-\mathrm{MoNi} / \mathrm{Al}_{2} \mathrm{O}_{3}$, which "separates" active metal and carrier in some extent and thereby weaken the metal-carrier interaction.

\subsubsection{Influences on the Acids Distribution and Acid Amount}

The major impacts of promoter on the acid amount and acids distribution are fulfilled through the following five kinds of mechanisms: first, it is modulated by ion exchange, mainly some metal promoters; second, the modulation is achieved in the way of promoting the dispersion degree of active metal; third, "covering" effect; fourth, the acidity also can be modulated by some promoters that are inherently acidic, such as transition metal ions; fifth, the modulation can be obtained by substitution reaction between skeleton aluminum and promoter. Sometimes, one promoter may have, simultaneously, several roles to modulate, therefore, to optimize its content and impregnation orders to get desired acidity is important.

$\mathrm{Mg}, \mathrm{K}, \mathrm{P}$ and $\mathrm{W}$ all own the ability to modulate the acidity of catalyst. $\mathrm{Mg}$ can promote the dispersion degree of metal component and hence make the metal surface present more electron-deficient sites; as a result, the number of $\mathrm{L}$ acid is increased. e.g., the density of $\mathrm{L}$ acid of (w) $2 \% \mathrm{Mg}-(\mathrm{w}) 7 \% \mathrm{Mo}_{2} \mathrm{C} / \mathrm{HY}$ is nearly doubled compared to (w) $7 \% \mathrm{Mo}_{2} \mathrm{C} / \mathrm{HY}$ [20]. $\mathrm{K}$ usually makes the amount of $\mathrm{B}$ acid significantly reduced due to proton exchange between hydroxyl hydrogen on carrier surface and $\mathrm{K}[20,21]$. However, study [17] on $\mathrm{CoMo} / \gamma-\mathrm{Al}_{2} \mathrm{O}_{3}$ showed $\mathrm{K}$ mainly made $\mathrm{L}$ acid amount reduced. Study [18] about P-NiW/Y-SiO $-\mathrm{TiO}_{2}$ showed that both surface impregnation and co-impregnation methods resulted in significantly reduction of the total amount of acid, but in the case of co-impregnation, although $\mathrm{P}$ covered part of acid sites on the carrier's surface, simultaneously, the dispersion degree of active metals was improved, so that the amount of $\mathrm{L}$ acid was increased. The reason for the increase of $\mathrm{L}$ acid amount is the same to $\mathrm{Mg}$. In addition, $\mathrm{P}$ may substitute for the carrier's framework aluminum, more specifically, a framework aluminum hydroxyl of the zeolite would be substituted by two phosphorus hydroxyl, making B, L acid amounts modulated [24]. Transition metal ions such as $\mathrm{W}$ have empty orbits; their addition can make a well increase of the amount of acid [15, 45]

\subsubsection{Influences on the Pores Distribution and Specific Surface Area}

The realization of impact of promoters on pores distribution and specific surface area is mainly based on its influences on metal dispersion state.

Generally, with the increase of promoter content, the specific surface area and pore volume increase primarily 
and then decrease, i.e., there is an optimum point. For B-MoNi/ $/ \mathrm{Al}_{2} \mathrm{O}_{3}$ [22], W-Ni $2 \mathrm{P} / \mathrm{SBA}-15$ [15], Mo-Ni ${ }_{2} \mathrm{P} / \mathrm{SBA}-$ $15 /$ cordierite [16], when B (w) of $0.8 \%$, W (w) $3 \%$, Mo (w) $4.2 \%$, their specific surface area and pore volume are maximal, respectively. Such effect of B, W and Mo can be attributed to the impact of promoter content on the dispersion state of active metal. When the promoter content is low, the dispersion degree of the active metal is improved and thus the surface properties are ameliorated; on the contrary, if the content is too high, the active phase (or precursor) may aggregate together and block portion of the pores, resulting in the decrease of surface area and pore volume. But there are exceptions, e.g., $\mathrm{Mg}-\mathrm{Mo}_{2} \mathrm{C} / \mathrm{HY}[20,21]$, the pore volume and specific surface area primarily decrease and then increase with the increasing content of $\mathrm{Mg}$.

\subsection{Chelating Agents}

Chelating agents are typically organic compounds with donor atom having two or more available electrons. They are capable of binding metal ions to form chelates, such as NTA [8,52], EDTA [53], and CyDTA etc. Their common feature is that they can delay the sulfurization of promoter metal (Co) until the active metals (Mo, W) are fully sulfurized, avoiding the production of $\mathrm{Co}_{9} \mathrm{~S}_{8}$ phase that is thermodynamically unstable, which is conducive to the formation of the active phase of $\mathrm{Co}-\mathrm{W}(\mathrm{Mo})-\mathrm{S}$. Another remarkably notable feature of the chelating agents is that they can dramatically weaken the metalsupport interaction, but scarcely any impact on the dispersion degree of active phase, or even improve the dispersion degree of active phase [49,52]. The nature of chelating agents breaks through the traditional cognition which the improvement of metal dispersion can be achieved only by enhancing the metal-support interaction, and makes sulfurization and dispersion degree of the active phase unified in a certain extent, providing more ways for people to prepare highly active catalyst. For instance, $\mathrm{Yu}$ et al. [49] prepared $\mathrm{NiW} / \mathrm{Al}_{2} \mathrm{O}_{3}, \mathrm{NiW}-\mathrm{P} /$ $\mathrm{Al}_{2} \mathrm{O}_{3}, \mathrm{NiWP} / \mathrm{EDTA} / \mathrm{Al}_{2} \mathrm{O}_{3}$ three catalysts, their HDN activity for quinoline were improved as the order. The addition of EDTA in NiWP/EDTA $/ \mathrm{Al}_{2} \mathrm{O}_{3}$ made the average number of the stacking layers and the length of active phase crystal morphology reduced 0.3 layers and $1.2 \mathrm{~nm}$, respectively, with respect to $\mathrm{NiWP} / \mathrm{Al}_{2} \mathrm{O}_{3}$, making the aspect ratios of $\mathrm{NiWP} / \mathrm{EDTA} / \mathrm{Al}_{2} \mathrm{O}_{3}$ improved; moreover, the sulfurization degree of active metal is also pretty increased because of weak metal-carrier interacttion due to the addition of EDTA. If $\mathrm{NiW} / \mathrm{Al}_{2} \mathrm{O}_{3}$ is modified directly by EDTA, it may cause too high dispersion degree of the active phase, which is not conducive to the molecules adsorption and is harmful to the increase of corner and edge active sites. Thus, P actually played a role like bridge in this experiment.

\section{Carriers}

In the preparation process of carrier, pore structure should be primarily design and topology analysis in order to balance the specific surface area and diffusion resistance (mainly determined by pores diameter) $[11,40,54$, 55]. Generally speaking, the relation between pore diameter and specific surface area is mutually restrictive. But, the principal restricted condition for HDS activity is different for different reactants. In terms of macromolecules, the relatively larger pore diameter is more important than larger specific surface area [55,56]. Secondly, choosing a suitable carrier having moderate binding force with active metal is crucial. When the binding force is too strong, It will lead to the formation of the $\mathrm{Mo}(\mathrm{W})$ $\mathrm{O}-\mathrm{Al}$ and thus the lower type I active site during sulfurization, whereas the formation of the type II active site requires $\mathrm{Mo}(\mathrm{W})-\mathrm{O}-\mathrm{Al}$ bond is broken (at least partially broken). Oppositely, when the interaction is too weak, there is no doubt that it is not conducive to improving the dispersion degree of the active site and hence does harm to the HDS activity [26].

The most commonly used carrier of HDS catalyst is $\gamma-\mathrm{Al}_{2} \mathrm{O}_{3}$ in industry. But it chiefly has two disadvantages, one is the dispersed pores distribution and short pores diameter concentrating in shorter than $5 \mathrm{~nm}$ resulting in large diffusion limit for reactant and intermediate products [11]; the other is that its strong interaction with active metal oxide. These shortcomings make it increasingly can't meet the requirements of desulfurization. The typically mesoporous silica molecular sieve materials SBA-15, HMS and MCM-41 as the carrier of hydrofining catalyst have potential value in use. Their advantages are large specific surface area (about $1000 \mathrm{~m}^{2} / \mathrm{g}$ ), uniform controlled mesoporous $(5-30 \mathrm{~nm})$ and stable skeleton structure. Their disadvantages are weaker acidity which should be strengthen on the original basis in order to isomerize DBTs to molecules owning weaker steric hindrance for -S- [23,37], and weaker hydrothermal stability and mechanical strength, as well as too weak interaction with active metal. Those several factors limit its industrial application so that the modification study should be carried on which is commonly based on their surface Si-OH.

At present, the commonly used modification method of those disadvantages is to introduce $\mathrm{Al}[28,37,55] \mathrm{Ti}$ [54], $\mathrm{Zr}$ [56], W [45], etc. into the carrier's frame. The methods to add heteroatom are usually co-impregnation (grafted directly) and post-grafting. the former's weaknesses are that the difficulty to introduce heteroatom in the case of low PH (lower than 2) [28], and to obtain larger and regular pores of catalyst $[55,56]$; its merit is it 
makes the catalyst possess higher specific surface area than post-grafting; The advantages of the latter are pore expanding and isomorphous substitution [55]; its shortcoming is pore plugging and thus making the specific surface area significantly lower than the catalyst obtained by co-impregnation method. The principle of post-grafting is firstly hydrolyzing the aluminum source (e.g. ammonium hexafluoroaluminate) to be $\left[\mathrm{Al}(\mathrm{OH})_{4}\right]^{-}$, and then isomorphously substituting. Inspired by the princeple of post-grafting, Li et al. [28] developed a new method named high-temperature hydrothermal treatment (HTHT) to solve the pore blockage problem of post-grafting. [Al $\left.(\mathrm{OH})_{4}\right]^{-}$can be easily formed by $\mathrm{Al}^{3+}$ and $\mathrm{Al}-\mathrm{OH}$ in condition of high-temperature hydrothermal; the other key of the method is that $\mathrm{PH}$ should be isoelectric point nearby to generate lots of $\mathrm{Si}-\mathrm{OH}$, and finally through the following reaction to complete graft.

$$
\mathrm{Si}-\mathrm{OH}+\mathrm{HO}-\mathrm{Al} \rightarrow \mathrm{Si}-\mathrm{O}-\mathrm{Al}+\mathrm{H}_{2} \mathrm{O}
$$

Besides the preparation method, a crucial parameter need to be optimized is the content of heteroatom, which is closely related to the dispersion degree of active phase and acids distribution of catalyst etc. e.g., the HDS performance of $\mathrm{NiMo} / \mathrm{TiSBA}-15$ on coke light gas oil (KLGO) was the best when $\mathrm{Si} / \mathrm{Ti}$ mole ratio was 20 . Research of NiMo/Zr-SBA-15 (synthesized directly) also had similar result [56].

Along with more and more heavy oil and increasingly strict laws of environmental protection, single carrier based catalyst already cannot meet the demand. Composite carrier commonly shows more excellent HDS activity than single carrier, such as $\mathrm{Al}_{2} \mathrm{O}_{3}-\mathrm{ZrO}_{2}$ [57], $\mathrm{Al}_{2} \mathrm{O}_{3}-\mathrm{SiO}_{2}$ [40], $\mathrm{TiO}_{2}-\mathrm{SiO}_{2}$ [31], Beta-SBA-15 [37], $\mathrm{TiO}_{2}-\mathrm{SBA}-15$ [25] and $\mathrm{ZrO}_{2}-\mathrm{SBA}-15$ [25,26,32,56]. In those carriers preparation process, the most important design parameter is the proportion of carrier contents in one composite carrier, because the proportion has an important relation with pores diameter, specific surface area, acids distribution and intensity, as well as metal-carrier interaction [31, 40]. e.g., $\mathrm{ZrO}_{2}-\mathrm{SBA}-15$, the optimal quality ratio of $\mathrm{ZrO}_{2} / \mathrm{SBA}-15$ is generally $1: 3[25,26,32]$; as to $\mathrm{SiO}_{2-}$ $\mathrm{Al}_{2} \mathrm{O}_{3}$, when $\mathrm{SiO}_{2} / \mathrm{Al}_{2} \mathrm{O}_{3}$ quality ratio was $1: 10$, the HDS activity and inactivation rate can reach a satisfactory balance [40].

It is greatly worth to mention that carrier on nanometer level has dramatically better performance on acidity, pore structure and carrier-metal interaction than carrier on micrometer level $[23,58]$. e.g., HDS degree of $\mathrm{NiMo} /$ $\mathrm{Al}_{2} \mathrm{O}_{3}-\mathrm{nmY}$ was increased by $0.8 \%$ compared to $\mathrm{NiMo} /$ $\mathrm{Al}_{2} \mathrm{O}_{3}$-umY, and the rate constant of the former is 3.46 times the latter [23]. In addition, the carriers on nanometer level can protect molecular sieve from poisoning and shorten diffusion path for raw material [58]. In total, its advantages are highly obvious. But, its preparation faces many problems, such as the need of expensive structure-directing-agent, and demanding strict reaction temperature in the synthesis process etc. In addition, the cordierite honeycomb ceramics monolithic catalyst [16] has the advantages of low bed pressure drop and high mass transfer efficiency, etc. over traditional hydrogenation catalysts, and hence also attracts researchers' attention From the above analysis, we can see that carrier's development trend is multicomponent and smaller particle size.

\section{Discussion on Desulfurization Catalyst That Is Suitable for Low Temperature Coal Tar}

Coal tars can be divided into three categories according to the coal pyrolysis temperature: high temperature coal tar, medium temperature coal tar and low temperature coal tar. The low temperature coal tar is the most suitable one to produce fuel oil because of its lower aromatics and asphalt content and higher alkane content. Typically, sulfur compounds in coal tar include thiol, sulfoether, disulfides, thiophene series and dibenzothiophene series. The commonly grading sequence of coal tar hydrotreating catalysts is: protection catalyst, demetallization catalyst, HDS catalyst, HDN catalyst, mild hydrocracking catalyst, which calls for hydrofining catalysts have some cracking ability. A pilot research [59] showed that catalysts used in heavy oil hydrotreating process are feasibly used for hydrotreating of low temperature coal tar. However, coal tar has its own characteristics; the following will theoretically discuss the suitable HDS catalyst for low temperature coal tar in the case of this kind of grading sequence.

First of all, its acid density and strength should be controlled, more specifically, the acidity should be stronger than demetallization catalyst and weaker than hydrodenitrification catalyst. That is because, on one hand, nitrogen content $(0.48 \%-1.13 \%)$ is high in coal tar [2], and the nitrogen with alkaline will poison the catalyst and inhibit HDS because of the competition effect of HDN; on the other hand, the moderate acidity can make $\mathrm{HC}$ and HDS well occur, moreover, can inhibit the formation of coke. Secondly, coal tar is a complex mixture, the sizes of sulfur compound molecules in coal tar are greatly different, that means these molecules need different degree of cracking and hydrogenation; moreover, aromatics content is very high in coal tar, and mainly tricyclic or above anthracene series. Those kinds of characteristics of coal tar require catalyst possesses different pores distribution and active sites distribution, namely, the activity in larger pores should be higher than in smaller pores in theory, which will match to the different reaction degree that is required by mixed molecu- 
lar. That needs to explore more elaborate catalyst preparation methods. Thirdly, HDS catalyst is relatively near the front of grading sequence; hence, material flowing through HDS catalyst is very heavy, the catalyst should have powerful capacity of treating aromatics including aromatics adsorption and diffusion, as well as more effective hydrogenation and ring opening ability. This requires catalyst possesses more lattice defects, secondary pores and excellent synergy between hydrogenation and cracking sites, In addition, appropriate number of large pores $(100-500 \mathrm{~nm})$ is also important. This primarily need to develop a new metal loading concept to increase the quantity of lattice defects, and amount of secondary pores can be added through hydrothermal treating and synthesis of composite molecular sieve. Finally, coal tar contains much asphalt whose structure is very complex, the polycyclic aromatic hydrocarbons in asphalt are bonded by the sulfur bridge bond, aliphatic bond and metal porphyrin bond. The structures of nickel and vanadium porphyrin compounds are similar to polycyclic aromatic hydrocarbons in asphalt, leading to abundant poisonous metals exists in it, moreover, part of the asphalt would generate carbon deposit by condensation polymerization and graphitization reaction, these carbon deposit can jam the channel and cover the active sites of catalyst and thereby making HDS catalyst inactivation. To solve this problem, the hydrogenation and cracking sites should have well synergetic effect. For the problem of catalyst poisoning, it can be eased by adding some nanometer oxides in support [58].

\section{Conclusions and Prospect}

1) Transition phosphide, carbide and nitride catalyst possess potential practical value for oil hydrotreating. But there are also some drawbacks must be further improved. The main drawback of the phosphide is the lower dispersion degree; the use rate of unit mass catalyst related to the phosphide sites is low. Transition metal carbides and nitrides catalyst own higher initial activity for hydrorefining, but in the using process, the active phase will be gradually sulfurized, making the catalytic activity decline. To further overcome these shortcomings, it will make them become a new generation catalyst for hydrotreating. In addition, the combination of non-sul-fide metal catalyst with the sulfide catalysts may also be a research direction.

2) Promoter or chelating agent can improve the active phase dispersion degree, acids distribution, pores distribution and metal-carrier interaction. Metal-carrier interaction is closely relevant to the crystal morphology of active phase. The using of promoter-chelating has important significance to develop novel catalyst preparation methods. We need to further develop new promoter (chelating agent), on one hand, to expand the catalyst preparation methods and to improve its thermal stability, mechanical properties and activity, on the other hand, to weaken the contradictions related to the performances of catalyst.

3) Composite and nanometer carriers can provide more appropriate acidity, pore structure and metal-carrier interaction than conventional carriers, but its thermal stability and mechanical properties are need to be further improved. To develop new preparation method is the key for the use of the composite and nanometer carriers.

The catalyst "design" problem is an "optimization" problem, and a system analysis should be given in process of catalyst preparation. The crucial factors to improve the activity of HDS catalyst are higher sulfurization degree and higher aspect ratios of the active phase crystal morphology. In addition, moderate acidity and proper pores structure could be considered the key factors of deep desulfurization.

\section{Acknowledgements}

We are grateful to many of our colleagues for stimulating discussions on desulfurization and hydrogenation. We would like to acknowledge the financial supports from Science and Technology Innovation Project of Shanxi Province in China (2011KTZB03-03-01) and Major Scientific and Technological Innovation Project of Shaanxi in China (2008zkc03205).

\section{REFERENCES}

[1] Y. Zhang and L. F. Zhao, "Study on Hydro Catalysis of Middle/Low Temperature Coal Tar to Clean Fuel," Coal Conversion, Vol. 32, No. 3, 2009, pp. 49-51.

[2] B. Q. Ma, P. J. Ren, Z. B. Yang and S. K. Wang, "Preparation of Fuel Oil from Coal Tar," Chemical Industry Press, Beijing, 2011.

[3] B. Pawelec, R. M. Navarro, J. M. Campos-Martin and J. L. G. Fierro, "Towards near Zero-Sulfur Liquid Fuels: A Perspective Review," Catalysis Science \& Technology, No. 1, 2011, pp. 23-42. doi:10.1039/c0cy00049c

[4] L. Lan, S. H. Ge, K. H. Liu, Y. D. Hong and X. J. Bao, "Synthesis of $\mathrm{Ni}_{2} \mathrm{P}$ Promoted Trimetallic Ni MoW $/ \gamma-\mathrm{Al}_{2} \mathrm{O}_{3}$ Catalysts for Diesel Oil Hydrotreatment," Journal of $\mathrm{Na}$ tural Gas Chemistry, Vol. 20, No. 2, pp. 117-122.

[5] L. Zhang, X. Y. Long, D. D. Li and X. D. Gao, "Study on High-Performance Unsupported Ni-Mo-W Hydrotreating Catalyst," Catalysis Communications, Vol. 12, No. 11, 2011, pp. 927-931.

[6] Y. Zhao, M. W. Xue, M. H. Cao and J. Y. Shen, "A Highly Loaded and Dispersed $\mathrm{Ni}_{2} \mathrm{P} / \mathrm{SiO}_{2}$ Catalyst for the Hydrotreating Reactions," Applied Catalysis B: Environmental, Vol. 104, No. 3-4, 2011, pp. 229-233.

[7] C. Sepulveda, V. Bellière, D. Laurenti, N. Escalona and R. García, "Supported Rhenium Sulfide Catalysts in Thio- 
phene and 4,6-Dimethyldibenzo Thiophene Hydrodesulfurization: Effect of Acidity of the Support over Activities," Applied Catalysis A: General, Vol. 393, No. 1-2, 2011, pp. 288-293.

[8] A. E. Coumans, D. G. Poduval, J. A. Rob van Veen and E. J. M. Hensen, "The Nature of the Sulfur Tolerance of aAmorphous Silica-Alumina Supported NiMo(W) Sulfide and Pt Hydrogenation Catalysts," Applied Catalysis A: General, Vol. 411-412, 2012, pp. 51-59.

[9] V. L. Parola, M. L. Testa and A. M. Venezia, "Pd and PdAu Catalysts Supported over 3-MPTES Grafted HMS Used in the HDS of Thiophene," Applied Catalsis B: Environmental, Vol. 119-120, 2012, pp. 248-255. doi:10.1016/j.apcatb.2012.03.007

[10] A. Infantes-Molina, J. A. Cecilia, B. Pawelec, J. L. G. Fierro and E. Rodríguez-Castellón, " $\mathrm{Ni}_{2} \mathrm{P}$ and CoP Catalysts Prepared from Phosphite-Type Precursors for HDSHDN Competitive Reactions," Applied Catalysis A: General, Vol. 390, No. 1-2, 2010, pp. 253-263. doi:10.1016/j.apcata.2010.10.019

[11] P. E. Boahene, K. K. Soni, A. K. Dalai and J. Adjaye, "Application of Different Pore Diameter SBA-15 Supports for Heavy Gas Oil Hydrotreatment Using FeW Catalyst", Applied Catalysis A: General, Vol. 402, No. 1-2, 2011, pp. 31-40.

[12] S. Chouzier, T. Czeri, M. Roy-Auberger, C. Pichon and C. Geantet, "Decomposition of Molybdate-Hexamethylenetetramine Complex: One Single Source Route for Different Catalytic Materials," Journal of Solid State Chemistry, Vol. 184, No. 10, 2011, pp. 2668-2677.

[13] Q. Ma, P. H. Zeng, S. F. Ji, H. Liu and C. Y. Li, "Effect of Metal Promoters on the Structure and Performance of the $\mathrm{Ni}_{2} \mathrm{P} / \mathrm{SBA}-15$ Catalyst for Hydrodesulfurization," Acta Petrolei Sinica (Petroleum Processing Section), Vol. 27, No. 2, 2011, pp. 175-180.

[14] P. F. Zhao, S. F. Ji, N. Wei, Q. Ma and H. Liu, "Effect of Boron Promoter on the Structure and HydrodesuIfurization Activity of Ni2P/SBA-15 Catalysts," Acta PhysicoChimica Sinica, Vol. 27, No. 7, 2011, pp. 1737-1742.

[15] N. Wei, S. F. Ji, Y. M. Guan, H. Liu and C. Y. Li, "Influence of $\mathrm{W}$ on Structure and Hydrodesulfurization Performance of $\mathrm{W}-\mathrm{Ni}_{2} \mathrm{P} / \mathrm{SBA}-15$ Catalysts," Acta Petrolei Sinica (Petroleum Processing Section), Vol. 27, No. 6, 2011, pp. 852-858.

[16] Y. N. Guo, P. H. Zeng, S. F. Ji and N. Wei, "Effect of Mo Promoter Contenton Performance of Mo- $\mathrm{Ni}_{2} \mathrm{P} / \mathrm{SBA}-15 /$ Cordierite Monolithic Catalyst for Hydrodesulfurization," Chinese Journal of Catalysis, Vol. 31, No. 3, 2010, pp. 329-334.

[17] M. X. Qin, B. Yu, J. Yang and H. J. Li, "Effects of Metal Modification on Selectivity of Co-Mo/ $\gamma-\mathrm{Al}_{2} \mathrm{O}_{3}$ Hydrodesulifcation Catalyst," Industrial Catalysis, Vol. 17, No. 5, 2009, pp. 45-49.

[18] Y. S. Zhou, Q. Wei, T. Zhang and X. J. Tao, "Effect of Phosphoric Modification on the Heavy Oil Hydrotreating Performance of NiW/CTS Catalysts," Journal of Fuel Chemistry and Technology, Vo1. 39, No. 10, 2011, pp. 766-770.

[19] D. W. Hui, Q. H. Yang, S. L. Sun and C. F. Niu, "Effect of Phosphorus on the Performance and Active Component Structure of $\mathrm{MoCoNi} / \mathrm{Al}_{2} \mathrm{O}_{3}$ Catalyst," Petroleum Processing and Petrochemicals, Vol. 42, No. 5, 2011, pp. $1-4$.

[20] S. J. Ardakani and K. J. Smith, "A Comparative Study of Ring Opening of Naphthalene, Tetralin and Decalin over $\mathrm{Mo} 2 \mathrm{C} / \mathrm{HY}$ and $\mathrm{Pd} / \mathrm{HY}$ Catalysts," Applied Catalysis A: General, Vol. 403, No. 1-2, 2011, pp. 36-47. doi:10.1016/j.apcata.2011.06.013

[21] X. B. Liu, S. J. Ardakani and K. J. Smith, "The Effect of $\mathrm{Mg}$ and $\mathrm{K}$ Addition to a Mo2C/HY Catalyst for the Hydrogenation and Ring Opening of Naphthalene," Catalysis Communications, Vol. 12, No. 6, 2011, pp. 454-458.

[22] S. K. Maity, M. Lemus and J. Ancheyta, "Effect of Preparation Methods and Content of Boron on Hydrotreating Catalytic Activity," Energy \& Fuels, Vol. 25, No. 7, 2011, pp. 3100-3107.

[23] H. L. Yin, T. N. Zhou, Y. Q. Liu, Y. M. Chai and C. G. Liu, "NiMo/ $\mathrm{Al}_{2} \mathrm{O}_{3}$ Catalyst Containing Nanosized Zeolite Y for Deep Hydride Sulfurization and Hydrodenitrogenation of Diesel," Journal of Natural Gas Chemistry, Vol. 20, No. 4, 2011, pp. 441-448. doi:10.1016/S1003-9953(10)60204-6

[24] Q. Wei, Y. S. Zhou, X. J. Tao, T. Zhang and Y. D. Liu, "Catalytic Activities of PY Zeolite Supported Hydrotreating Catalyst," Acta Petrolei Sinica (Petroleum Processing Section), Vol. 28, No. 1, 2012, pp. 15-20.

[25] T. Klimova, O. Gutiérrez, L. Lizama and J. Amezcua, "Advantages of $\mathrm{ZrO}_{2}$ - and $\mathrm{TiO}_{2}-\mathrm{SBA}-15$ Mesostructured Supports for Hydride Sulfurization Catalysts over Pure $\mathrm{TiO}_{2}, \mathrm{ZrO}_{2}$ and SBA-15," Microporous and Mesoporous Materials, Vol. 133, 2010, pp. 91-99.

[26] O. Y. Gutiérrez and T. Klimova, "Effect of the Support on the High Activity of the $(\mathrm{Ni}) \mathrm{Mo} / \mathrm{ZrO}_{2}-\mathrm{SBA}-15$ Catalyst in the Simultaneous Hydridesulfurization of DBT and 4,6-DMDBT," Journal of Catalysis, Vol. 281, 2011, pp. 50-62.

[27] R. Nava, A. Infantes-Molina, P. Castao, R. Guil-López and B. Pawelec, "Inhibition of CoMo/HMS Catalyst Deactivation in the HDS of 4,6-DMDBT by Support Modification with Phosphate," Fuel, Vol. 90, No. 8, 2011, pp. 2726-2737. doi:10.1016/j.fuel.2011.03.049

[28] Y. Li, D. H. Pan, C. Z. Yu, Y. Fan and X. J. Bao, "Synthesis and Hydrodesulfurization Properties of NiW Catalyst Supported on High-Aluminum-Content, Highly Ordered, and Hydrothermally Stable Al-SBA-15," Journal of Catalysis, Vol. 286, 2012, pp. 124-136. doi:10.1016/i.jcat.2011.10.023

[29] N. Malicki, G. Mali, A. A. Quoineaud, P. Bourges and L. J. Simon, "Aluminium Triplets in Dealuminated Zeolites Detected by ${ }^{27} \mathrm{Al}$ NMR Correlation Spectroscopy," Microporous and Mesoporous Materials, Vol. 129, No. 1-2, 2010, pp. 100-105.

[30] M. Nakamura, "Nanometer Catalyst Technology to Reduce the Dosage of Noble Metal," Foreign Internal Combustion Engine, Vol. 3, 2011, pp. 35-39.

[31] R. K. Sharma, B. S. Rana, D. Varma, R. Kumar and R. Tiwari, "3-D Mesoporous Titanosilicate Support for Highly Effective Hydrodesulfurization Catalysts," Micro- 
porous and Mesoporous Materials, Vol. 155, 2012, pp. 177-185.

[32] D. Valencia and T. Klimova, "Effect of the Support Composition on the Characteristics of NiMo and $\mathrm{CoMo} /$ (Zr)SBA-15 Catalysts and Their Performance in Deep Hydrodesulfurization," Catalysis Today, Vol. 166, 2011, pp. 91-101.

[33] Y. Kanda, C. Temma, K. Nakata, T. Kobayashi and M. Sugioka, "Preparation and Performance of Noble Metal Phosphides Supported on Silica as New Hydrodesulfurization Catalysts," Applied Catalysis A: General, Vol. 386, No. 1-2, 2010, pp. 171-178. doi:10.1016/j.apcata.2010.07.045

[34] S. W. Gong, L. J. Liu, H. F. He and Q. X. Cui, "Dibenzothiophene Hydrodesulfurization over $\mathrm{MoP} / \mathrm{SiO}_{2}$ Catalyst Prepared with Sol-Gel Method," Korean Journal of Chemical Engineering, Vol. 27, No. 5, 2010, pp. 14191422. doi:10.1007/s11814-010-0234-3

[35] T. Kan, H. Y. Wang, H. X. He, C. S. Li and S. J. Zhang, "Experimental Study on Two-Stage Catalytic Hydroprocessing of Middle-Temperature Coal Tar to Clean Liquid Fuels," Fuel, Vol. 90, No. 11, 2011, pp. 3404-3409. doi:10.1016/j.fuel.2011.06.012

[36] Z. H. Yang, L. C. Li, Y. F. Wang, J. L. Liu and X. Feng, "Preparation of Nickel Phosphide/Mesoprous-TiO ${ }_{2}$ Catalyst and Its Hydrodesulfurization Performance," Chinese Journal of Catalysis, Vol. 33, No. 3, 2012, pp. 508-517.

[37] D. Q. Zhang, A. J. Duan, Z. Zhao, X. Q. Wang and G. Y. Jiang, "Synthesis, Characterization and Catalytic Performance of Meso-Microporous Material Beta-SBA-15Supported NiMo Catalysts for Hydrodesulfurization of Dibenzothiophene," Catalysis Today, Vol. 175, No. 1, 2011, pp. 477-484. doi:10.1016/j.cattod.2011.03.060

[38] J. Francis, E. Guillon, N. Bats, C. Pichon and A. Corma, "Design of Improved Hydrocracking Catalysts by Increasing the Proximity between Acid and Metallic Sites," Applied Catalysis A: General, Vol. 409-410, 2011, pp. 140-147.

[39] G. Q. Cui, J. F. Wang, H. F. Fan, X. Y. Sun and Y. Jiang, "Towards Understanding the Microstructures and Hydrocracking Performance of Sulfided Ni-W Catalysts: Effect of Metal Loading," Fuel Processing Technology, Vol. 92, No. 12, 2011, pp. 2320-2327. doi:10.1016/j.fuproc.2011.07.020

[40] C. Leyva, J. Ancheyta, A. Travert, F. Maugé and L. Mariey, "Activity and Surface Properties of $\mathrm{NiMo} / \mathrm{SiO}_{2}$ $\mathrm{Al}_{2} \mathrm{O}_{3}$ Catalysts for Hydroprocessing of Heavy Oils," Applied Catalysis A: General, Vol. 425-426, 2012, pp. 1-12.

[41] L. B. Pierella, C. Saux, S. C. Caglieri, H. R. Bertorello and P. G. Bercoff, "Catalytic Activity and Magnetic Properties of Co-ZSM-5 Zeolites Prepared by Different Methods," Applied Catalysis A: General, Vol. 347, No. 1, 2008, pp. 55-61.

[42] S. G. A. Ferraz, F. M. Z. Zotin, L. R. R. Araujo and J. L. Zotin, "Influence of Support Acidity of NiMoS Catalysts in the Activity for Hydrogenation and Hydrocracking of Tetralin," Applied Catalysis A: General, Vol. 384, No. 1-2, 2010, pp. 51-57.

[43] Y. J. Wang, H. J. Zhang, B. Sun and X. G. Tian, "Re- search Progress of $\mathrm{WO}_{3} / \mathrm{ZrO}_{2}$ in Alkane Isomerization," Acta Petrolei Sinica (Petroleum Processing Section), Vol. 25, No. 2, 2009, pp. 283-290.

[44] M. X. Du, Zh. F. Qin, H. Ge, X. K. Li and Z. J. Lü, "Enhancement of Pd-Pt/ $\mathrm{Al}_{2} \mathrm{O}_{3}$ Catalyst Performance in Naphthalene Hydrogenation by Mixing Different Molecular sSieves in the Support," Fuel Processing Technology, Vol. 91, No. 11, 2010, pp. 1655-1661. doi:10.1016/j.fuproc.2010.07.001

[45] L. Dimitrov, R. Palcheva, A. Spojakina and K. Jiratova, "Synthesis and Characterization of W-SBA-15 and WHMS as Supports for HDS," Journal of Porous Materials, Vol. 18, No. 4, 2011, pp. 425-434.

[46] H. Shimada, K. Sato, K. Honna, T. Enomoto and N. Ohshio, "Design and Development of Ti-Modified ZeoliteBased Catalyst for Hydrocracking Heavy Petroleum," Catalysis Today, Vol. 141, No. 1-2, 2009, pp. 43-51. doi:10.1016/j.cattod.2008.04.012

[47] A. Nogueira, R. Znaiguia, D. Uzio, P. Afanasiev and G. Berhault, "Curved Nanostructures of Unsupported and $\mathrm{Al}_{2} \mathrm{O}_{3}$-Supported $\mathrm{MoS}_{2}$ Catalysts: Synthesis and HDS Catalytic Properties," Applied Catalysis A: General, Vol. 429-430, 2012, pp. 92-105.

[48] V. L. Parola, B. Dragoi, A. Ungureanu, E. Dumitriu and A. M. Venezia, "New HDS Catalysts Based on Thiol Functionalized Mesoporous Silica Supports," Applied Catalysis A: General, Vol. 386, No. 1-2, 2010, pp. 43-50.

[49] G. L. Yu, Y. S. Zhou, Q. Wei, X. J. Tao and Q.Y. Cui, “A Novel Method for Preparing Well Dispersed and Highly Sulfided NiW Hydridenitrogenation Catalyst," Catalysis Communications, Vol. 23, 2012, pp. 48-53. doi:10.1016/j.catcom.2012.03.002

[50] M. Ke, X. Y. Wang, Z. Q. Zhang, Z. Z. Song and Q. Z. Jiang, "Preparations and Properties of Selective Hydrodesulfurization Catalysts for FCC Gasoline," Petrochemical Technology, Vol. 40, No. 2, 2011, pp. 133-139.

[51] C. Q. Li, J. W. Li, X. K. Shang, H. Wang and G. D. Sun, "Dibenzothiophene Hydrodesulfurization Performance of WP/MCM-41 Catalysts Containing Cobalt," Acta Petrolei Sinica (Petroleum Processing Section), Vol. 27, No. 6, 2011, pp. 859-865.

[52] M. A. Lélias, P. J. Kooyman, L. Mariey, L. Oliviero and A. Travert, "Effect of NTA Addition on the Structure and Activity of the Active Phase of Cobalt-Molybdenum Sulfide Hydrotreating Catalysts," Journal of Catalysis, Vol. 267, No. 1, 2009, pp. 14-23. doi:10.1016/j.jcat.2009.07.006

[53] M. A. Lélias, E. Le. Guludec, L. Mariey, J. van Gestel and A. Travert, "Effect of EDTA Addition on the Structure and Activity of the Active Phase of Cobalt-Molybdenum Sulfide Hydrotreatment Catalysts," Catalysis Today, Vol. 150, No. 3-4, 2010, pp. 179-185. doi:10.1016/j.cattod.2009.07.107

[54] K. K. Soni, K. C. Mouli, A.K. Dalai and J. Adjaye, "Effect of Ti Loading on the HDS and HDN Activity of KLGO on NiMo/TiSBA-15 Catalysts," Microporous and Mesoporous Materials, Vol. 152, 2012, pp. 224-234.

[55] K. C. Mouli, K. Soni, A. Dalai and J. Adjaye, "Effect of Pore Diameter of Ni-Mo/Al-SBA-15 Catalysts on Thehy- 
drotreating of Heavy Gas Oil," Applied Catalysis A: General, Vol. 404, No. 1-2, 2011, pp. 21-29.

doi:10.1016/j.apcata.2011.07.001

[56] P. Biswas, P. Narayanasarma, C. M. Kotikalapudi, A. K. Dalai and J. Adjaye, "Characterization and Activity of $\mathrm{ZrO}_{2}$ Doped SBA-15 Supported NiMo Catalysts for HDS and HDN of Bitumen Derived Heavy Gas Oil," Industrial \& Engineering Chemistry Research, Vol. 50, No. 13, 2011, pp. 7882-7895.

[57] M. A. Al-Daous and S. A. Ali, "Deep Desulfurization of Gas Oil over NiMo Catalysts Supported on Alumina-Zir- conia Composites," Fuel, Vol. 97, 2012, pp. 662-669.

[58] T. Kimura, K. Sakashita, X. H. Li and S. Asaoka, "Catalytic Roles of Nano-Sized Oxides Composed with Zeolite for Hydrocracking, Catalytic Cracking and Reforming," Catalysis Surveys from Asia, Vol. 15, 2011, pp. 259-266.

[59] C. Li, W. A. Deng, X. W. Li, B. Q. Mu and S. F. Li, "Pilot Tests of Medium/Low Temperature Coal Tar Oil Hydro-Upgrading with Heavy Oil Hydro-Treating Catalysts," Petroleum Refinery Engineering, Vol. 41, No. 9, 2011, pp. 32-35. 